\title{
Effect of Insulin Treatment or Zinc Supplementation on Vitamin A Status in Streptozotocin-Induced Diabetic Rats
}

\author{
Prisca Tuitoek, ${ }^{1}$ Jonathan Lakey, ${ }^{2}$ Ray Rajotte, ${ }^{2}$ \\ Shahed ZIARI, ${ }^{3}$ Andrew TsIN,${ }^{3}$ and Tapan BASU ${ }^{1, *}$ \\ ${ }^{1}$ Department of Agricultural, Food and Nutritional Science, and \\ ${ }^{2}$ Surgical-Medical Research Institute, University of Alberta, \\ Edmonton, Alberta, Canada T6G 2P5 \\ ${ }^{3}$ Division of Life Sciences, The University of Texas at San Antonio, \\ San Antonio, Texas 78249-0662, U.S.A.
}

(Received August 2, 1995)

\begin{abstract}
Summary Using streptozotocin-induced diabetic rats, we examined the effects of zinc supplementation and insulin treatment on the metabolic availability of vitamin A. All diabetic animals exhibited an elevated plasma glucose ( $>18 \mathrm{mmol} /$ liter) level within $48 \mathrm{~h}$ of intravenous streptozotocin injection. The untreated diabetic rats exhibited a reduction in body weight gain, with a $50 \%$ increase in daily food intake. In diabetic animals treated with insulin for 4 weeks, the plasma glucose, body weight gain, and daily food intake were comparable to those of the non-diabetic controls. The plasma concentration of vitamin A was significantly reduced in the diabetic animals, whereas the hepatic content of vitamin $\mathrm{A}$ in them was significantly elevated. Treatment with implantable insulin resulted in both plasma and liver concentrations of vitamin A returning to the control non-diabetic levels. Dietary zinc supplementation $(120 \mu \mathrm{g} / \mathrm{g}$ diet for 4 weeks) failed to improve the plasma concentration of vitamin A. These results suggest that the impaired metabolic availability of vitamin $\mathrm{A}$ in the presence of diabetes is caused by insulin deficiency.
\end{abstract}

Key Words: streptozotocin-induced diabetes, vitamin A status, insulin effect, dietary zinc effect

The metabolic availability of vitamin A (retinol) has been shown to be impaired in diabetes mellitus, as indicated by decreased levels of plasma retinol and its carrier, retinol-binding protein (RBP), in patients with insulin-dependent

*To whom correspondence should be addressed. 
diabetes mellitus (IDDM) [1-3]. It has further been shown that diabetic patients not only have reduced plasma retinol but also elevated levels of retinyl esters [4], reflecting an increased hepatic storage [5]. Streptozotocin (STZ)-induced diabetic rats have decreased plasma retinol levels that are accompanied by an elevated hepatic concentration of vitamin A [6]. The decreased plasma level of the vitamin remains unchanged in the diabetic animals even when they consume a diet supplemented with 10 times the basal level of vitamin A, while their hepatic levels of the vitamin markedly increase [7]. The underlying cause for the depressed circulatory level of vitamin A despite its increased concentrations in the liver is not well understood. According to an in vitro study [8], the intestinal absorption of retinol does not appear to be affected by STZ-induced diabetes.

The retinol carrier proteins, such as RBP and transthyretin (TTR), have been found to be decreased in the plasma and liver, as well as in the kidney, of STZ-induced diabetic rats [9], suggesting an impaired mobilization of vitamin A from its hepatic storage to the circulation. Zinc is required for the synthesis of RBP $[10,11]$ and has been shown to promote the transport of vitamin A from the liver $[12,13]$. Since zinc metabolism is known to be perturbed in the presence of diabetes [14-17], it is possible that supplementation with this trace element may enhance the hepatic synthesis of RBP and thereby reverse the decreased plasma retinol found in diabetes.

Using STZ-induced diabetic rats, we undertook the present study to investigate the effects of a zinc supplement to the diet and insulin treatment on plasma and liver vitamin A levels. The objective of the study was to examine if these treatments would reverse the diabetes-associated decrease in metabolic availability of vitamin A.

\section{MATERIALS AND METHODS}

Animals and diet. Male Wistar rats (Cr1: (WI) BR), weighing 225-250 g, were obtained from Charles River, Montreal, Canada. They were housed in stainless steel cages in a well-ventilated room maintained at $21^{\circ} \mathrm{C}$ and on a $12-\mathrm{h}$ light-dark cycle. Diabetes was induced by a single intravenous injection $(55 \mathrm{mg} /$ $\mathrm{kg}$ ) of streptozotocin (STZ; Upjohn, Kalamazoo, MI) dissolved in citrate buffer (pH 4.5). Control rats were injected with acetate buffer alone. Following injection of streptozotocin, animals displaying a plasma glucose level of greater than 18 mmol/liter were considered diabetic. Experimental protocols were reviewed and approved by the Animal Policy and Welfare Committee, University of Alberta.

Animals were divided into four groups: Group A was the non-diabetic control; and the remaining groups were all diabetics without (group B) or with (group C) zinc supplementation or treated with insulin (group D). All animals were allowed free access to a semisynthetic diet (Table 1) for 4 weeks. Group C rats were fed the semisynthetic diet supplemented with zinc sulfate $(120 \mu \mathrm{g} / \mathrm{g}$ diet $)$.

Insulin treatment. Group D was treated with implantable insulin. The 7-mm 
Table 1. Composition of the semi-synthetic diet. ${ }^{1}$

\begin{tabular}{lc}
\hline Ingredient & $\%$ \\
\hline Casein (vitamin free) & 20 \\
Corn starch & 60 \\
Non-nutritive bulk & 5 \\
Corn oil & 10 \\
AIN vitamin-mix (with choline) ${ }^{2}$ & 1.25 \\
AIN mineral mixture & 3.5 \\
Methionine $^{1}$ & 0.25 \\
\hline
\end{tabular}

${ }^{1}$ Ingredients except corn oil were from ICN Biomedicals, Cleveland, Ohio. ${ }^{2}$ Retinyl acetate in the diet, $12 \mathrm{IU} / \mathrm{g}$ diet. Vitamin mixture, $\mathrm{g} / \mathrm{kg}$ mixture: vitamin $\mathrm{A}$ acetate $(500,000 \mathrm{IU} / \mathrm{g})$, 1.98; vitamin $\mathrm{D}_{2}(850,000 \mathrm{IU} / \mathrm{g}), 0.138$; vitamin $\mathrm{E}$ acetate $(500 \mathrm{IU} / \mathrm{g}), 11.0$; ascorbic acid, 49.5; inositol, 5.5; choline bitartrate, 222.7; menadione, 2.475; $p$-aminobenzoic acid, 5.5; niacin, 4.675; riboflavin, 1.1: pyridoxine $\mathrm{HCl}, 1.1$; thiamin $\mathrm{HCl}, 1.1$; D-calcium pantothenate, 3.3; biotin, 0.022; folic acid, 0.099; vitamin $\mathrm{B}_{12}, 0.00149 .{ }^{3}$ Mineral mixture, $\mathrm{g} / \mathrm{kg}$ mixture: calcium phosphate diabasic, 500; sodium chloride, 74; potassium citrate monohydrate, 220; potassium sulfate, 52 ; magnesium oxide, 24 ; manganous carbonate ( $43-48 \% \mathrm{Mn}), 3.5$; ferric citrate $(16-17 \% \mathrm{Fe}), 6$; zinc carbonate $(70 \% \mathrm{ZnO}), 1.6$; cupric carbonate $(53-55 \% \mathrm{Cu}), 0.3$; potassium iodate, 0.01 ; sodium selenite, 0.01 ; chromium potassium sulfate, 0.55 .

long and 2-mm diameter implants were fabricated by high pressure compression of a powder of bovine insulin and re-crystallized palmitic acid (Linshin Canada, Ontario). Unlike insulin given by injection, the implant releases a set basal dose of insulin continuously throughout the day. The rats in this study were less than $300 \mathrm{~g}$ in body weight, and each received 1.5 implants resulting in an insulin release rate of 3 units per day.

The animals were anesthetized with halothane, the neck region was shaved, and the implant was inserted. After the shaved spot had been cleansed with betadine, the skin was pinched between the thumb and index fingers. The skin was then pierced with a $16 \mathrm{G}$ disposable hypodermic needle and the needle withdrawn. The trocar was immersed briefly in $2 \%$ betadine solution; then it was pushed through the skin orifice just created to a length of at least $2 \mathrm{~cm}$. The implant was immersed briefly in the $2 \%$ betadine solution and then inserted into the proximal end of the trocar. The trocar rod was then used to push the implant until it exited from the distal end of the trocar. The skin was pinched over the inserted implant, before withdrawing the trocar, and closed with a single surgical skin staple.

Sample collection. A record of food intake and body weight was kept weekly. Animals were killed at the end of the study by use of carbon dioxide. Blood was collected in heparinized tubes; separated plasma was protected from light and stored at $-20^{\circ} \mathrm{C}$, pending analysis. Livers were removed, cleaned, and frozen immediately in liquid nitrogen.

Biochemical analysis. Plasma [18] and liver [19] vitamin A were assayed by high-performance liquid chromatography (HPLC) with retinyl acetate (Sigma Chemical Co., St. Louis, MO) used as the internal standard. For extraction of 
retinol from plasma, $200 \mu 1$ plasma samples were pipetted into microcentrifuge tubes. The internal standard, $200 \mathrm{ng} / \mathrm{ml}$ of retinyl acetate dissolved in acetonitrile, was then added and vortexed for $15 \mathrm{~s}$. A total of $250 \mu 1$ of butanol : ethyl acetate (1:1) was added and then vortexed again for $60 \mathrm{~s}$. Finally, $150 \mu 1$ of an aqueous solution of dipotassium monohydrogen phosphate $(1.2 \mathrm{~g} / \mathrm{ml})$ was added, and the solution vortexed for a further $30 \mathrm{~s}$. It was then centrifuged at 9,000 rpm for $1 \mathrm{~min}$ to separate the phases. The organic upper layer was injected into the HPLC. For each sample, duplicate aliquots were extracted. All procedures were performed in dim light, and solutions containing vitamin A were protected from light. Liver samples were homogenized in 9 volumes $(\mathrm{wt} / \mathrm{v})$ of water in a Polytron homogenizer for $20 \mathrm{~s}$. The homogenate was then saponified with an equal volume of $5 \%$ potassium hydroxide in methanol for $1 \mathrm{~h}$ at $50^{\circ} \mathrm{C}$. The saponified liver samples were extracted with hexane, which was subsequently removed under vacuum in a Savant spin evaporator. Residues were dissolved in acetonitrile and then injected into the HPLC.

The HPLC equipment used consisted of a Waters 600E Multi-delivery system pump (Waters Associates, Milford, MA), a Waters 486 tunable ultraviolet/visible absorbance detector, and a Waters computer recorder equipped with a Millenium software integrator. A reverse phase, C18 column (Whatman partisil) was used with an isocratic solvent system of methanol : water $(95: 5)$ at a flow rate of $1.5 \mathrm{ml} /$ min. All solvents used were HPLC grade, and the mobile phase was filtered and de-gassed before each run. Detection was by UV absorption at $325 \mathrm{~nm}$, and quantification was performed by comparison of ratio of peak areas produced by the injection of known amounts of retinol and an amount of internal standard equal to that in the samples.

Zinc content of tissues was analyzed by atomic absorption spectrophotometry (Perkin Elmer Model) with a zinc standard (Aldrich Chemical Co.). All glassware was rinsed in diluted nitric acid and deionized water to avoid any contamination [20]. Standards were prepared by diluting the stock standard solutions with saline.

Plasma was diluted 1/10 with deionized water. Liver samples were analyzed for zinc by modification of the method used by Oster et al. [21]. Weighed liver samples were dried in preweighed porcelain crucibles for $23 \mathrm{~h}$ at $110^{\circ} \mathrm{C}$ and cooled in a desiccator. Concentrated sulphuric acid $\left(\mathrm{H}_{2} \mathrm{SO}_{4}\right)$ was added, and the samples were digested on a block heater for $40 \mathrm{~min}$. A mixture of concentrated nitric acid/ perchloric acid (72\%) $/ \mathrm{H}_{2} \mathrm{SO}_{4}$, by volume $8: 2: 3$, was added; and digestion continued for a further 30 min until a clear solution was produced. The cooled solution was transferred quantitatively to a volumetric flask, diluted with deionized water, and mixed for analysis.

Plasma glucose concentrations were measured by the glucose oxidase method by use of a Beckman Glucose Analyzer [22].

Statistical analysis. Data were tabulated to give means and standard errors of the mean by use of the SAS computer program [23]. The four treatments were compared by one-way analysis of variance (ANOVA) [24]. When significant 
differences were detected by ANOVA, the appropriate comparisons were made. The level of significance was set at $p<0.05$.

\section{RESULTS}

All diabetic animals exhibited elevated plasma glucose $(>18 \mathrm{mmol} / \mathrm{liter})$ levels within $48 \mathrm{~h}$ of STZ injection. The untreated diabetic rats exhibited a reduction in body weight gain, while their daily food intake was approximately $50 \%$ more than that of the controls (Table 2). In diabetic animals treated with insulin for 4 weeks, the plasma glucose, body weight gain and daily food intake were at the non-diabetic control levels. However, this was not the case with diabetic animals fed a zinc-supplemented diet. These animals displayed mean body weight gain, daily food intake, and plasma glucose level similar to those of the untreated diabetic rats.

The plasma and liver vitamin A concentrations are shown in Table 3. Plasma concentrations of vitamin A were significantly reduced, whereas the hepatic content of the vitamin was elevated in the diabetic as compared with that of the non-diabetic control rats. When diabetic animals were treated with insulin, the vitamin A status in both plasma and the liver were comparable to the levels observed in control non-diabetic animals. Zinc supplementation, however, failed to show this effect. Thus the diabetic rats fed a diet containing zinc, $120 \mu \mathrm{g} / \mathrm{g}$ for 4 weeks, had circulatory and hepatic concentrations of vitamin A similar to those of untreated diabetic animals.

Table 2. Effect of insulin treatment and zinc supplementation on various parameters. ${ }^{1}$

\begin{tabular}{lcccc}
\hline & $\begin{array}{c}\text { Body weight } \\
\text { gain }(\mathrm{g})\end{array}$ & $\begin{array}{c}\text { Mean daily } \\
\text { food intake }(\mathrm{g})\end{array}$ & $\begin{array}{c}\text { Plasma glucose } \\
(\mathrm{mmol} / \mathrm{liter})\end{array}$ & $\begin{array}{c}\text { Liver wt } \\
(\mathrm{g})\end{array}$ \\
\hline Control & $154 \pm 10.3^{\mathrm{a}}$ & $21.8 \pm 2.10^{\mathrm{a}}$ & $6.9 \pm 2.03^{\mathrm{a}}$ & $14.2 \pm 0.7^{\mathrm{a}}$ \\
Diabetic & $48 \pm 9.5^{\mathrm{b}}$ & $42.3 \pm 1.95^{\mathrm{b}}$ & $20.7 \pm 1.54^{\mathrm{b}}$ & $12.7 \pm 0.6^{\mathrm{a}}$ \\
Diabetic, zinc supplemented & $47 \pm 10.3^{\mathrm{b}}$ & $44.5 \pm 2.10^{\mathrm{b}}$ & $20.6 \pm 1.66^{\mathrm{b}}$ & $12.9 \pm 0.7^{\mathrm{a}}$ \\
Diabetic, insulin treated & $144 \pm 9.5^{\mathrm{a}}$ & $22.1 \pm 1.95^{\mathrm{a}}$ & $8.2 \pm 1.82^{\mathrm{a}}$ & $12.1 \pm 0.6^{\mathrm{a}}$ \\
\hline
\end{tabular}

${ }^{1}$ Results are expressed as mean \pm SEM at least five animals. ${ }^{a, b}$ Letters not shared show significance $(p<0.05)$ as analyzed by Scheffe's test.

Table 3. Effect of insulin treatment and zinc supplementation on plasma and liver vitamin A concentrations in STZ-induced diabetic rats. ${ }^{1}$

\begin{tabular}{lcc}
\hline & $\begin{array}{c}\text { Plasma retinol } \\
(\mu \mathrm{mol} / \text { liter })\end{array}$ & $\begin{array}{c}\text { Liver vitamin A } \\
(\mu \mathrm{mol} / \mathrm{g})\end{array}$ \\
\hline Control & $1.25 \pm 0.03^{\mathrm{a}}$ & $0.41 \pm 0.06^{\mathrm{a}}$ \\
Diabetic & $0.95 \pm 0.04^{\mathrm{b}}$ & $1.08 \pm 0.07^{\mathrm{b}}$ \\
Diabetic, zinc supplemented & $0.96 \pm 0.04^{\mathrm{b}}$ & $1.06 \pm 0.07^{\mathrm{b}}$ \\
Diabetic, insulin treated & $1.33 \pm 0.03^{\mathrm{a}}$ & $0.43 \pm 0.07^{\mathrm{a}}$ \\
\hline
\end{tabular}

${ }^{1}$ Results are expressed as mean \pm SEM at least five animals. ${ }^{a, b}$ Letters not shared show significance $(p<0.05)$ as analyzed by Scheffe's test.

Vol. 19, No. 3, 1995 
Table 4. Effect of insulin treatment and zinc supplementation on plasma and liver zinc levels in STZ-induced diabetic rats. ${ }^{1}$

\begin{tabular}{llc}
\hline & $\begin{array}{l}\text { Plasma zinc } \\
(\mu \mathrm{mol} / \mathrm{liter})\end{array}$ & $\begin{array}{c}\text { Liver zinc } \\
(\mu \mathrm{mol} / \mathrm{g} \text { dry wt })\end{array}$ \\
\hline Control & $18.9 \pm 1.3$ & $1.93 \pm 0.06^{\mathrm{a}}$ \\
Diabetic & $18.4 \pm 1.25$ & $2.24 \pm 0.06^{\mathrm{b}}$ \\
Diabetic, zinc supplemented & $18.4 \pm 1.35$ & $2.36 \pm 0.06^{\mathrm{b}}$ \\
Diabetic, insulin treated & $17.4 \pm 1.47$ & $2.02 \pm 0.06^{\mathrm{a}}$ \\
\hline
\end{tabular}

${ }^{1}$ Results are expressed as mean \pm SEM at least five animals. ${ }^{a, b}$ Letters not shared show significance $(p<0.05)$ as analyzed by the Student-Newman-Keuls test.

The zinc concentrations in the plasma and liver are shown in Table 4. Plasma zinc concentrations were not affected by diabetes, and remained unaffected by either zinc supplementation or insulin treatment. However, the liver concentrations of zinc were 16 and $22 \%$ higher in diabetic and zinc-supplemented diabetic groups, respectively, than in the non-diabetic animals.

\section{DISCUSSION}

The results of the present study show that plasma levels of retinol were significantly lower, whereas its hepatic concentrations were significantly higher, in the diabetic than in the control animals. These results are in agreement with earlier studies on humans or rats [1-7]. The increased liver concentrations of vitamin A may be explained in part by the increased food intake by the diabetic animals $(>50 \%)$, since it has been shown that the hepatic storage of vitamin A is proportional to its intake [25].

Insulin treatment with implantable, slow-release insulin implants in diabetic rats in this study was found to restore plasma retinol levels to the values observed in non-treated control rats. This is in agreement with a previous study in which plasma retinol was restored to normal levels in diabetic rats treated with a single dose of insulin once a day for 3 weeks [19]. In that study, however, the insulin treatment failed to alter the diabetes associated increased hepatic vitamin A concentrations. This was not the case in the present study where insulin treatment not only restored plasma retinol but also reduced the liver oncentration of vitamin A to its control value. The difference between the results of the two studies might be explained by the time at which insulin treatment was started and the mode of insulin treatment. In the present study, the insulin treatment was started at the onset of diabetes while in the previous study, treatment began 3 weeks after the onset of diabetes. Thus it is possible that the diabetic animals were able to store large quantities of vitamin $\mathrm{A}$ in the liver within the 3 weeks before they were treated with insulin. In the previous study insulin treatment once a day did not appear to cause much reduction in the mean daily food intake when the intake in the untreated and insulin-treated diabetic groups was compared. The insulin- 
treated animals had a mean daily food intake $37.7 \%$, and the untreated diabetic group, $46.9 \%$, more than that of the non-diabetic controls. Therefore this increased food intake in the insulin-treated diabetic animals may have contributed in part to the increased hepatic storage of vitamin A. Insulin treatment of nondiabetic rats has been shown to increase the rate of depletion of vitamin A from the liver [25]. The results of the present study appear to support this finding because the hepatic concentration of vitamin A of the insulin-treated group was significantly lower than that of the untreated diabetic animals and was not different from that of the control group.

It should be noted that treatment with STZ, due to its hepatoxicity [26], may interfere with the release of vitamin A from the liver. However, the effect of insulin in restoring plasma vitamin A to normal levels suggests that the defect in the vitamin A metabolism of STZ-induced diabetic rats is primarily due to the insulin-deficient state of the animals rather than to a direct hepatoxic effect of STZ. Moreover, plasma vitamin A has been found to be lower in IDDM patients than in non-diabetic subjects [1].

The decreased plasma concentrations of retinol have been suggested to be due to a deficiency of zinc, which metal ion is required for the synthesis of the RBP, the protein that binds retinol in the liver for secretion into the plasma [11]. Thus, in situations such as in alcoholic cirrhosis, where reduced plasma vitamin $\mathrm{A}$ is accompanied by a poor zinc status, vitamin A supplementation alone did not improve the abnormal dark adaptation suffered by the patients [10]. However, normalization was accomplished when vitamin A was supplemented with zinc, suggesting that these patients had an inability to mobilize vitamin A from the liver. In the present study zinc was used as a supplement in order to examine if this inorganic element promotes the mobilization of vitamin A from its hepatic stores to the plasma. No effect of zinc supplementation was, however, found on either plasma or hepatic vitamin A levels. It is possible that the duration of diabetes was not long enough to cause a significant effect on the zinc status. It is noteworthy that while plasma zinc levels remained unaffected the hepatic concentrations were elevated in the presence of diabetes. These results are in parallel with those of others, who found increased hepatic zinc levels in diabetic animals [17, 27, 28]. The fact that there were no differences in hepatic zinc levels between the zincsupplemented and the unsupplemented diabetic rats suggest that the observed changes are due to the insulin deficiency. This is supported by the normalization of hepatic zinc levels by insulin treatment. The accumulation of zinc in the diabetic liver has been suggested to be caused by increased levels of metallothionein, a zinc-binding cytoplasmic protein $[17,27]$. The hormones such as glucagon, glucocorticoid, and epinephrine are known to be stimulators of hepatic synthesis of this protein [29]. It is thought that insulin deficiency induces synthesis of these hormones and that this effect leads to an increase in hepatic metallothionein and zinc levels in the liver [27]. 


\section{REFERENCES}

1. Basu, T.K., Tze, W.J., and Leichter, J. (1989): Serum vitamin A and retinol-binding protein in patients with insulin-dependent diabetes mellitus. Am. J. Clin. Nutr., 50, 329-331.

2. Krempf, M., Ranganathan, S., Ritz, P., Morin, M., and Charbonnel, B. (1991): Plasma vitamin $\mathrm{A}$ and $\mathrm{E}$ in type 1 and type 2 adult diabetic patients. Int. J. Vitam. Nutr. Res., 61, $38-42$.

3. Martinoli, L., Di Felice, M., Seghieri, G., Ciuti, M., De Giorgio, L.A., Fazzine, A., Gori, R., Anachini, R., and Franconi, F. (1993): Plasma retinol and $\alpha$-tocopherol concentrations in insulin-dependent diabetes mellitus: Their relationship to microvascular complications. Int. J. Vitam. Nutr. Res., 63, 87-92.

4. Wako, Y., Suzuki, K., Goto, Y., and Kimura, S. (1986): Vitamin A transport in plasma of diabetic patients. Tohoku J. Exp. Med., 149, 133-143.

5. Smith, F.R., and Goodman, D.S. (1976): Vitamin A transport in human vitamin A toxicity. N. Engl. J. Med., 294, 805-808.

6. Basu, T.K., Leichter, J., and McNeill, J.H. (1990): Plasma and liver vitamin A concentrations in streptozotocin diabetic rats. Nutr. Res., 10, 421-427.

7. Tuitoek, P.J., Ziari, S., Tsin, A.T.C., Rajotte, R.V., Suh, M., and Basu, T.K. (1996): Streptozotocin-induced diabetes in rats is associated with impaired metabolic availability of vitamin A (retinol). Br. J. Nutr. (in press).

8. Tuitoek, P.J., Thomson, A.B.R., Rajotte, R.V., and Basu, T.K. (1994): Intestinal absorption of vitamin A in streptozotocin-induced diabetic rats. Diabetes Res., 25, 151-158.

9. Tuitoek, P.J., Ritter, S.J., Smith, J.E., and Basu, T.K. (1996): Streptozotocin-induced diabetes and plasma vitamin A (retinol) carrier proteins. Br. J. Nutr. (in press).

10. Morrison, S.A., Russel, R.M., Carney, E.A., and Oaks, E.V. (1978): Zinc deficiency: A cause of abnormal dark adaptation in cirrhotics. Am. J. Clin. Nutr., 31, 278-281.

11. Ette, S.I., Basu, T.K., and Dickerson, J.W.T. (1979): Short-term effects of zinc sulphate on plasma and hepatic concentrations of vitamin $\mathrm{A}$ and $\mathrm{E}$ in normal weanling rat. Nutr. Metab., 23, 11-16.

12. Smith, J.C., Jr. (1980): The vitamin A-zinc connection: A review. Ann. N.Y. Acad. Sci., 355, $62-75$.

13. Smith, J.E., Brown, E.D., and Smith, J.C. (1974): The effect of zinc deficiency on the metabolism of retinol-binding protein in the rat. J. Lab. Clin. Med., 84, 692-697.

14. Kinlaw, W.B., Levine, A.S., Morley, J.E., Silvis, S.E., and McClain, C.J. (1983): Abnormal zinc metabolism in type II diabetes mellitus. Am. J. Med., 75, 273-277.

15. Lau, A., Failla, M.L. (1984): Urinary excretion of zinc, copper and iron in the streptozotocin-induced rat. J. Nutr., 114, 224-233.

16. Walter, R.M., Uri-Hare, J.Y., Olin, K.L., Oster, M.H., Anawalt, B.D., Critchfield, J.W., and Keen, C.L. (1991): Trace element status and complications of diabetes mellitus. Diabetes Care, 14, 1050-1056.

17. Uri-Hare, J.Y., Walter, R.M., and Keen, C.L. (1992): ${ }^{65} \mathrm{Zinc}$ metabolism is altered during diabetic pregnancy in rats. J. Nutr., 122, 1988-1998.

18. Nierenberg, D.W., and Lester, D.C. (1985): Determination of vitamin A and E in serum and plasma using a simplified clarification method and high-performance liquid chromatography. J. Chromatogr., 345, 275-284.

19. Leichter, J., McNeill, J.H., Basu, T.K., and Dunn, B.P. (1991): Influence of insulin on plasma and liver vitamin A levels in diabetic rats. J. Clin Biochem. Nutr., 11, 47-52.

20. Liska, S.K., Kerkay, J., and Person, K.H. (1985): Determination of zinc in whole blood, plasma and serum using Zeeman effect flame atomic absorption spectroscopy. Clin. Chem. Acta, 151, 237-243.

21. Oster, O., Dahm, M., Oelert, H., and Prellwitz, W. (1989): Concentrations of some trace 
elements ( $\mathrm{Se}, \mathrm{Zn}, \mathrm{Cu}, \mathrm{Fe}, \mathrm{Mg}, \mathrm{K})$ in blood and heart of patients with coronary heart disease. Clin. Chem., 35, 851-855.

22. Kadish, A.H., Little, R.L., and Shernberg, J.C. (1968): A new and rapid method for the determination of glucose by measurement of rate of oxygen consumption. Clin. Chem., 14, $116-131$.

23. SAS Institute Inc., SAS/STAT User's Guide, Release 6.03 Edition. Cary, NC : SAS Institute Inc., 1988.

24. Steel, R.G.D., and Torrie, J.H. (1980): Principles and Procedures of Statistics: A Biometrical Approach, McGraw-Hill, New York, pp. 67-119.

25. Bowles, W.H. (1967): Influence of insulin on liver vitamin A in rats. Diabetes, 16, 704-707.

26. Chang, A.Y. (1981): Streptozotocin-induced alterations in enzyme activities in animals, in Streptozotocin: Fundamentals and Therapy, ed. Agarwal, M.K., Elsevier/North Holland, Amsterdam, pp. 111-126.

27. Failla, M.L., and Kiser, R.A. (1983): Hepatic and renal metabolism of copper and zinc in the diabetic rat. Am. J. Physiol., 244, E115-E121.

28. Raz, I., and Havivi, E. (1988): Influence of chronic diabetes on tissue and blood cells status of zinc, copper and chromium in the rat. Diabetes Res., 7, 19-21.

29. Cousins, R.J., Dunn, M.A., Leinart, A.S., Yedinak, K.C., and DiSilvestro, R.A. (1986): Coordinate regulation of zinc metabolism and metallothionein gene expression in rats. $\mathrm{Am}$. J. Physiol., 251, E688-E694. 